\title{
REFLEXÕES SOBRE A PREPARAÇÃo E O ACOMPANHAMENTO DE FAMÍLIAS NA ADOÇÃO
}

\author{
MONICA DE VASCONCELLOS DIAS \\ UNIVERSIDADE VEIGA DE ALMEIDA \\ RIO DE JANEIRO, RIO DE JANEIRO, BRASIL \\ MONIVAS.DIASO@GMAIL.COM
}




\section{REFLEXÕES SOBRE A PREPARAÇÃo E O ACOMPANHAMENTO DE FAMÍLIAS NA ADOÇÃO}

Resumo: Esse trabalho apresenta e discute as perspectivas da preparação e do acompanhamento de famílias interessadas na adoção, a partir das mudanças propostas pelas novas diretrizes da legislação (Lei n. 8.069/1990 e Lei 12.10/2009), que estabelecem a necessidade de uma preparação psicossocial para a habilitação para a adoção. São apresentadas aqui diferentes perspectivas sobre esse processo de preparação para a adoção, com ênfase nas propostas desenvolvidas pelos Grupos de Apoio à Adoção.

Palavras-chave: Preparação para adoção; Habilitação para adoção; Grupos de Apoio à Adoção.

\section{REFLEXIONES SOBRE LA PREPARACIÓN Y EL SEGUIMIENTO DE LAS FAMILIAS EN ADOPCIÓN}

Resumen: Este trabajo presenta y discute las perspectivas de preparación y monitoreo de las familias interesadas en la adopción, con base en los cambios propuestos por las nuevas directrices legislativas (Ley 8.069 / 1990 y Ley 12.10 / 2009), que establecen la necesidad de preparación psicosocial para el calificación para la adopción. Aquí se presentan diferentes perspectivas sobre este proceso de preparación para la adopción, con énfasis en las propuestas desarrolladas por los Grupos de Apoyo a la Adopción.

Palabras Clave: Preparación para la adopción; Calificación para adopción; Grupos de apoyo de adopción.

\section{REFLECTIONS ON THE PREPARATION AND MONITORING OF FAMI- LIES IN ADOPTION}

Abstract: This work presents and discusses the perspectives of preparation and monitoring of families interested in adoption, based on the changes proposed by the new legislation guidelines (Law 8.069 / 1990 and Law 12.10 / 2009), which establish the need for psychosocial preparation for the qualification for adoption. Different perspectives on this process of preparation for adoption are presented here, with an emphasis on the proposals developed by the Adoption Support Groups.

Keywords: Preparation for adoption; Qualification for adoption; Adoption Support Groups.

\section{INTRODUÇÃO}

Este trabalho apresenta e discute as perspectivas do processo de preparação e acompanhamento de famílias que se constituem pela via da adoção. 
A adoção é vista como um processo psicossocial e jurídico que demanda um acompanhamento para assegurar o direito de crianças e adolescentes à convivência familiar. Essa visão apoia-se no Estatuto da Criança e do Adolescente, Lei n. 8.069/1990, que prevê a adoção como uma medida para garantir que crianças e adolescentes, que não puderam ser criados por suas famílias de origem, por abandono, negligência, maus-tratos, entre outras situações, sejam inseridos em famílias substitutas. Contudo, a inclusão de crianças e adolescentes em famílias substitutas deve ser realizada, apenas depois de esgotadas todas as possibilidades para a sua reintegração na família de origem. O que pode levar algum tempo, e exigir um trabalho efetivo de transformação das condições adversas que desencadearam o seu afastamento das famílias de origem.

Para ser efetivada, a adoção deve ser considerada o melhor interesse da criança ou do adolescente para a manutenção de uma convivência familiar. De acordo com a legislação (Lei n. 8.069/1990 e Lei n. 12.10/2009), a inserção da criança ou do adolescente na família adotiva deve ser precedida de uma preparação, para assegurar que esta nova convivência possa oferecer condições para o atendimento das necessidades de desenvolvimento e afeto destes. A preparação visa ajustar as expectativas e demandas das crianças, adolescentes e famílias, propiciando uma ressignificação de suas histórias e uma construção conjunta de possibilidades para a estruturação de novos vínculos familiares. Assim, a preparação para a adoção é um processo que deve ser realizado tanto com os pretendentes, pai e mãe, quanto com as crianças e adolescentes, filhos.

No que se refere aos pretendentes, à preparação psicossocial visa promover reflexões sobre suas motivações para a maternidade e paternidade, sua disponibilidade para acolher as necessidades do filho, sensibilizando-os para a escolha de um perfil etnicamente variado, que considere não só os bebês e crianças menores, mas, também, os grupos de irmãos, crianças maiores ou com problemas de saúde. Ampliando, assim, suas disponibilidades afetivas para o acolhimento, como filho, de crianças e adolescentes com um perfil mais amplo, contribuindo, também, para uma maior compreensão sobre a realidade vivenciada por estes antes da adoção.

A adoção focada nas necessidades das crianças e dos adolescentes, que se constituem como filhos, e não dos adultos, que acolhem essa filiação, é relativamente nova. Ao longo da história, a adoção foi vista, primordialmente, como uma forma daqueles que não puderam ter filhos biológicos consti- 
tuírem uma descendência. Na visão atual, a adoção é considerada um direito das crianças e dos adolescentes de terem uma família e os adultos, que desejam acolhê-los, devem se habilitar nas Varas da Infância e Juventude de suas comarcas. Essa habilitação implica em uma avaliação das condições psicossociais e jurídicas da família interessada na adoção. Essa perspectiva insere a adoção numa prática intermediada pelo poder judiciário, afastando-a da prática cultural da circulação informal de crianças, que era realizada diretamente entre a família biológica e a família adotiva, estabelecendo a necessidade de avaliação, preparação e acompanhamento daqueles que desejam adotar e daqueles que serão adotados. (CAMPOS, 2001; FONSECA, 2006; WEBER, 2009; BORTOLATTO, LOOS e DELVAN, 2016)

A preparação para a adoção é considerada uma etapa necessária e fundamental para a formação dessa família, na medida em que visa informar aos participantes sobre as características do processo de adoção e potencializar suas capacidades para acolher as necessidades das crianças e adolescentes como filhos. Nesse sentido, constitui-se como um processo no qual os adotantes vão refletir sobre vários aspectos relevantes ao universo adotivo. Entre estes, destacamos a importância da reflexão sobre as motivações para a adoção, o contato com a realidade das crianças/adolescentes a espera da adoção e a escolha de um perfil mais consciente e ajustado, compatibilizando as possibilidades dos adotantes com as necessidades daqueles que vão acolher como filhos. (SIQUEIRA e STELLA, 2014; SOUZA e CASANOVA, 2014; MORANI, 2017)

Deste modo, a preparação para a adoção implica em um processo de comprometimento, interno e afetivo, com a escolha pela adoção e com o percurso de formação desta nova família. Contribui para uma maior conscientização dos adultos, pretendentes, do ato que estão se propondo a realizar, das responsabilidades em acolher alguém como filho pela via da adoção. Configurando-se como um momento privilegiado para a reflexão sobre suas motivações, limites e possibilidades na busca de uma filiação adotiva. (SIQUEIRA e STELLA, 2014; SOUZA e CASANOVA, 2014; MORANI, 2017)

A preparação para a adoção constitui-se como um processo de orientação e acompanhamento daqueles que desejam acolher, como filhos, crianças e adolescentes a espera de uma família substituta. Essa preparação deve discutir, entre outras coisas, os aspectos jurídicos e psicológicos que envolvem a adoção. Em relação aos aspectos jurídicos, os parâmetros legais, que constituem a adoção como uma filiação legítima e voltada para o melhor 
interesse das crianças e adolescentes, devem ser temas constantes, assim como, a orientação sobre as etapas do processo jurídico da habilitação à adoção. No que se refere aos aspectos psicológicos, à preparação para a adoção deve se estruturar de forma a propiciar reflexões que permitam um contato empático dos habilitandos com as vivências e trajetórias de vulnerabilidades que marcam as vidas das crianças e adolescentes acolhidos. Igualmente significativa, é a reflexão dos pretendentes, pai e mãe, sobre seus percursos de vida, sobre sua busca pela adoção e sobre o modo como pretendem se organizar para a chegada desse filho.

\section{APRESENTANDO O PROCESSO DE PREPARAÇÃO PSICOSSOCIAL PARA A ADOÇÃO}

A preparação para a adoção foi estabelecida como parte obrigatória do processo de inclusão de crianças e adolescentes em uma família substituta pela Lei n. 12.010/2009. Atualmente, está incluída no Estatuto da Criança e do Adolescente (Lei n. 8.069/1990) como etapa integrante do processo de habilitação/ adoção. Preferencialmente esta preparação é desenvolvida pelas equipes técnicas das próprias Varas da Infância e Juventude de cada Comarca, mas, em várias regiões do Brasil, a preparação é realizada através de parcerias do Judiciário com os Grupos de Apoio a Adoção, formados por movimentos da sociedade civil. (BORTOLATTO, LOOS e DELVAN, 2016)

Nos Grupos de Apoio à Adoção (GAA), geralmente, a preparação para a adoção é realizada através de palestras, depoimentos e dinâmicas, que visam orientar e provocar reflexões nos participantes. Na preparação realizada pelas equipes técnicas das Varas da Infância e Juventude (VIJ), além das palestras informativas, são realizadas, também, entrevistas e estudos psicossociais. Assim, no processo de habilitação para a adoção, os procedimentos realizados pelas VIJ e pelos GAA se complementam, de modo a avaliar e potencializar a capacidade de acolhimento dos pais e mães adotivos. (BORTOLATTO, LOOS e DELVAN, 2016; BOHM et al. 2019)

$\mathrm{Na}$ habilitação para a adoção, cabe destacar que, embora a equipe técnica da Vara da Infância e Juventude (VIJ) e os Coordenadores dos Grupos de Apoio à Adoção (GAA) trabalhem em parceria para preparar as famílias, algumas diferenças no manejo desse processo se estabelecem, pela própria natureza do vínculo constituído entre estes e os habilitandos. A equipe técnica da VIJ, por mais que tenha uma postura acolhedora e próxima dos postulantes à adoção, tem um papel voltado, fundamentalmente, para a ava- 
liação das motivações e capacidades dos habilitandos para se tornarem pais de crianças e adolescentes que, por terem histórias de vida marcadas por vulnerabilidades variadas, não devem ser expostos a experiências que gerem mais sofrimento, por isso, precisam ser incluídos em famílias que possam, efetivamente, prover os cuidados necessários ao seu desenvolvimento. Assim, a responsabilidade desses profissionais é grande, na medida em que o estudo psicossocial realizado por eles vai embasar a decisão judicial para habilitar ou não essas famílias. Nesse sentido, predomina na relação entre técnicos e postulantes à adoção um viés de avaliação. (CAMPOS e COSTA, 2004; BOHM et al. 2019)

Na preparação para a adoção realizada pelos Grupos de Apoio à Adoção (GAA), por outro lado, privilegia-se a construção de um vínculo entre os postulantes e o grupo, de modo que este possa funcionar como um espaço de trocas, de orientação e de acolhimento, visando à construção de uma rede de apoio capaz de ampliar as possibilidades de acolhimento da família adotiva para as reais necessidades das crianças e adolescentes aguardando a adoção. O processo de preparação visa aprofundar as reflexões sobre as motivações para a adoção, promover uma "desidealização" do filho aguardado, estimular a transformação de mitos e preconceitos ligados à adoção, potencializando a capacidade dos futuros pais e mães adotivas para acolher as histórias e necessidades de seus filhos. (SIQUEIRA e STELLA, 2014; SOUZA e CASANOVA, 2014; MORANI, 2017)

Preparar, orientar e amparar novas construções de vínculos familiares nas situações de adoção, assim como proteger, defender e cuidar dos direitos das crianças e adolescentes é, na atualidade, uma proposta inovadora das redes de atenção às famílias brasileiras. Este campo é constituído por diferentes ressonâncias, nas quais os planos, as leis e os estatutos não conseguem, por si só, oferecer suporte nem às crianças abrigadas, nem às famílias que buscam crianças para adotar. A realidade do cotidiano com o trabalho de adoção exige preparação de todos os sistemas envolvidos: redes de atenção social, famílias, instituições públicas e filantrópicas, escolas e profissionais. (CARDOSO e BAIOCCHI, 2014, pag. 53,54 .)

Bohn, Campos, Santoucy, Peixoto, Lima, Rocha e Gurgel (2019) salientam o longo caminho que o campo da adoção vem percorrendo na transformação da visão da "adoção clássica", voltada para as expectativas das famílias sem descendência, para a "adoção moderna", focada nas ne- 
cessidades da criança ou do adolescente, sem condições de permanecer na família de origem, que encontram na convivência familiar adotiva o suporte necessário ao seu desenvolvimento e à construção de vínculos afetivos mais perenes.

A adoção contemporânea traz muitos desafios, entre eles o de conciliar duas necessidades: as das famílias que desejam adotar e a das crianças e adolescentes privados do convívio familiar. A adoção constitui-se como medida protetiva que legitima esse vínculo de filiação. Sendo necessária, nesse processo, uma preparação psicossocial e jurídica para a habilitação e para a efetivação da adoção. A preparação, que é etapa obrigatória do processo, é realizada, preferencialmente, pelas equipes técnicas das VIJ, mas, pode contar, também, em muitas comarcas, com a colaboração dos grupos de apoio à adoção.

\subsection{A preparação psicossocial e os grupos de apoio à adoção}

A preparação para a adoção realizada pelos Grupos de Apoio a Adoção tem formatos variados. Algumas se estruturam com número de encontros determinados, grupos fechados de participantes e discussões com temas fixos e sequenciais. Outras se configuram como reuniões abertas, com temas variados e grupo formado por pessoas em diferentes estágios do processo de habilitação. As coordenações dos grupos são constituídas, geralmente, por psicólogos voluntários, pais e mães adotivas que coordenam as reuniões mensais que, numa parceria com as Varas da Infância e Juventude de diversas Comarcas, constituem etapa obrigatória para os postulantes darem entrada ao processo de habilitação para a adoção. Além das reuniões obrigatórias, muitos grupos realizam encontros mensais com os já habilitados que aguardam na fila da adoção e com as famílias que já estão constituídas pela adoção.

A participação das famílias que estão se habilitando para a adoção nas reuniões mensais dos GAA já é uma etapa obrigatória para dar entrada ao processo. Contudo, a experiência tem demonstrado que aqueles que continuam frequentando as reuniões, mesmo após o período obrigatório, têm se beneficiado das orientações e do apoio que recebem nos grupos. Também após a habilitação, a espera pela criança/ adolescente, muitas vezes, é longa e gera ansiedade naqueles que estão aguardando pelo encontro com o seu futuro filho. Assim, continuar frequentando as reuniões dos GAA, nesse 
período, ajuda a lidar com a espera e fortalece emocionalmente os participantes. Da mesma maneira, após a inclusão da criança/ adolescente na família é fundamental poder contar com um espaço de apoio para o fortalecimento dos vínculos e o suporte ao período de adaptações na família.

Os grupos de apoio à adoção são constituídos por pais e mães adotivos e por profissionais (psicólogos, assistentes sociais, pedagogos, advogados, entre outros) que trabalham, geralmente de forma voluntária, para promover e apoiar o direito à convivência familiar de crianças e adolescentes. Constituindo-se como um espaço de encontros, trocas e reflexões, as reuniões nos grupos de apoio à adoção discutem temas do universo adotivo, ajudando as famílias a construírem e fortalecerem os seus vínculos através da "gestação afetiva" que caracteriza essa forma de filiação. Entendendo que a relação entre pais e filhos se constitui, fundamentalmente, pelos vínculos afetivos, compreendem que, para transformar uma criança/ adolescente em filho, é necessário "adotá-lo afetivamente".

Desta forma, o grupo de apoio à adoção tem como proposta promover, preparar e solidificar encontros entre pais e filhos, ajudando-os a se tornarem uma família pela via da adoção. Reconhecendo a adoção como uma forma legítima de constituir uma família, fortalecem essa escolha acolhendo-a como uma maneira amorosa de se estruturar vínculos, afastando-a, assim, da visão preconceituosa da adoção como uma "filiação de segunda classe" em relação à filiação biológica. Nesse sentido, Morani (2017, p.122) afirma que, "a adoção não é a escolha de um filho, e sim a maneira pela qual se escolhe gestá-lo.". A adoção, então, é uma forma legítima de se estruturar uma família e os filhos advindos dessa configuração desejam serem filhos legítimos de seus pais adotivos. (MORANI, 2017)

Acreditando nesse universo fértil da adoção e na gestação afetiva que nele se manifesta, o grupo tem como objetivo focar na importância da decisão de ser pai e mãe pela adoção como uma escolha possível, verdadeira e genuína, pois, realiza concretamente um projeto de vida que é fruto de um desejo e não do acaso, tornando-os verdadeiramente pais e geradores de uma história de vida que merece ser relatada sempre que se faça necessário. (MORANI, 2017, p. 122)

Seguindo essa diretriz, a preparação dos pais adotivos, realizada no grupo de apoio, procura estimular as competências e potencialidades destes para cuidar, através do acolhimento de suas dúvidas e demandas e do forta- 
lecimento dos vínculos entre eles, promovendo redes de apoio mais amplas. Além disso, para potencializar sua capacidade amorosa para acolher seus filhos, torna-se necessário, também, ajuda-los a compreender o universo adotivo e a realidade enfrentada por crianças e adolescentes que vivem em instituições de acolhimento e que foram afastadas do convívio com suas famílias biológicas, de modo a conscientizá-los da importância e da responsabilidade da escolha por serem pais e mães pela via da adoção.

Siqueira e Stella (2014) também discutem a preparação dos pretendentes à adoção a partir da experiência de um grupo de apoio. Na visão destas autoras, a preparação para a adoção é entendida como uma forma de "evitar dificuldades vinculares" da criança com a família adotiva, pressupondo que essas dificuldades de integração se devem, basicamente, a "conteúdos mal elaborados referentes à motivação para a adoção." (SIQUEIRA e STELLA, 2014, p. 67).

Siqueira e Stella(2014) sinalizam a necessidade de elaboração das histórias de sofrimento vivenciadas tanto pelos pais adotivos quanto pelas crianças e adolescentes adotados. Entendem que a preparação para a adoção envolve reflexão e discussão sobre os aspectos psicossociais, jurídicos, culturais e educacionais que envolvem esse processo, apontando a importância da reflexão sobre os preconceitos e discriminações que permeiam a adoção no imaginário social. Consideram que o trabalho com os pretendentes à adoção deve prepará-los para lidar com questões do processo, como a espera, o acolhimento e a construção de vínculos, que se apresentam como partes do processo de integração da criança/ adolescente a sua nova família.

De acordo com Siqueira e Stella (2014), a participação no grupo de apoio à adoção possibilita aos pretendentes ressignificarem conflitos e afetos, trabalhando os sentimentos e as emoções que são despertados pelo processo de adoção. Apontam como característica da participação no grupo a troca de experiências com outras pessoas que passam pela mesma situação, o que possibilita novas reflexões e ressignificações, que promovem uma desmistificação desse universo e favorecem a revisão de preconceitos, permitindo uma maior aproximação entre o perfil, antes idealizado, e a realidade das crianças e adolescentes a espera da adoção.

A preparação para a adoção realizada no grupo com outras pessoas na mesma situação "rompe com a sensação do candidato de ser diferente, de estar sozinho nesse sofrimento, gerando melhoras na autoestima e redução de estigmas relacionados às crianças a serem adotadas." (SIQUEIRA e 
STELLA, 2014, p. 70). O que promove uma ampliação dos repertórios emocionais e dos significados associados à adoção e à construção da filiação adotiva. Propiciando um espaço para a reflexão sobre as motivações para a adoção e para a emergência de conteúdos ligados as expectativas sobre o exercício da parentalidade.

Bortolatto, Loos e Delvan (2016), apontam que a preparação, a orientação e o acompanhamento, para adotantes e adotados, durante todo o processo de adoção, estão previstos na legislação atual. Contudo, ainda existem algumas dificuldades a serem superadas na efetivação desses procedimentos.

(...) os pretendentes que entram no processo de adoção brasileiro atual encontram algumas dificuldades, entre elas a demora e a quantidade de procedimentos exigidos (documentação, entrevistas, avaliações, cursos), a falta de acompanhamento e orientação no período de espera (que pode estender-se por anos de acordo com o perfil desejado), bem como a adequação de suas expectativas à realidade brasileira e o enfrentamento de questões como motivação e preparação para a chegada da criança. (BORTOLATTO, LOOS e DELVAN, 2016, p. 208)

Na busca para ampliar os recursos para a preparação e o acompanhamento de famílias em processos de adoção, a participação dos Grupos de Estudo e Apoio à Adoção tem se disseminado como alternativa viável para promover uma maior aproximação entre as necessidades das crianças e adolescentes e as demandas dos pais e mães adotivos. Nesses grupos, pais e mães por adoção e profissionais voluntários, conduzem atividades que promovem orientações e acolhimento aos pretendentes à adoção nas diversas fases do processo. Os grupos não avaliam os pretendentes, esta função é das VIJ, apenas acolhem as suas dúvidas e angústias, através do compartilhamento das experiências, com outras famílias que já passaram pelo mesmo percurso e com profissionais que lidam com a adoção em sua prática. A participação dos pretendentes nas reuniões dos GAAs não é obrigatória em muitas Comarcas, mas, é sempre recomendada. Em algumas comarcas, os GAA têm parcerias com o Judiciário na habilitação para a adoção e a participação em algumas reuniões nestes grupos é parte obrigatória do processo de habilitação. Contudo, embora desejável e estimulada, a continuidade da participação nas reuniões dos GAAs, após esse período obrigatório, é escolha voluntária dos habilitandos. 
(...) apesar de não ser sempre obrigatória a participação nos GEAA, muitos destes grupos contribuem com discussões e abordagens dos temas referentes à adoção, portanto é recomendada a participação nos mesmos não só antes, mas durante e depois do processo de adoção. (BORTOLATTO, LOOS e DELVAN, 2016, p. 208, 209)

Além da orientação e do suporte emocional, que a participação nos Grupos de Apoio à Adoção pode oferecer no período de habilitação e de espera na fila da adoção, as trocas de experiências, que ocorrem entre aqueles que frequentam as reuniões, contribui, também, para fortalecer os pais e mães adotivos no processo de educar seus filhos. Discutir as especificidades da filiação adotiva e do processo de integração das crianças/ adolescentes a nova família, tendo como suporte outras famílias que vivenciam a mesma realidade, contribui para a superação das dificuldades enfrentadas em seu cotidiano.

Bortolatto, Loos e Delvan (2016, p. 210), sinalizam que a adoção, e o processo de inclusão da criança/ adolescente em sua nova família, mobilizam "emoções intensas e carregadas de ambivalência" de ambos os lados. Na construção dessa relação, crianças/ adolescente e mães/ pais adotivos colocam em cena suas idealizações e referências, criando, muitas vezes, embates que estabelecem conflitos comuns a muitas famílias, mas, que podem ser vividos com uma intensidade maior na adoção, dada a carga de expectativas de ambos os lados. Assim, nesse processo, é necessário que os envolvidos entrem em contato com suas histórias, suas motivações e suas expectativas em relação à formação dos vínculos nessa nova família. O que torna fundamental a troca de experiências e o apoio oferecido pela participação dos pretendentes e dos pais e mães adotivas nas reuniões dos Grupos de Apoio à Adoção.

Cardoso e Baiocchi (2014, p.55) salientam a necessidade de trabalhar com as famílias em processo de adoção algumas especificidades dessa forma de filiação. As autoras chamam a atenção para o componente emocional da "gestação adotiva", para o tempo de sua efetivação e para o processo de superação de resistências, mitos e preconceitos, que acompanham, ao longo do percurso, a preparação das famílias. "A gestação do filho adotivo é igualmente geradora de angústias e ansiedades, ainda mais ao se pensar que é uma gestação sem prazo pré-determinado, ou seja, o filho pode "nascer" em poucas semanas ou demorar vários anos."

Cardoso e Baiocchi (2014, p. 55) apontam como questões específicas 
da adoção as incertezas variadas que colocam os pais adotivos em uma "montanha russa" de emoções, "ora esperançosos e eufóricos", "ora desanimados", pela falta de controle do processo, submetidos ao tempo e aos ditames jurídicos, temendo não saber lidar com a história anterior do filho e com sua ligação com a família biológica.

O principal objetivo daqueles que trabalham com a preparação para a adoção é tentar ajudar essas famílias a lidarem com os diversos sentimentos mobilizados, de forma a evitar ao máximo a interferência inadequada na construção dos vínculos afetivos com as crianças adotadas. (CARDOSO e BAIOCCHI, 2014, p. 56)

Cardoso e Baiocchi (2014) ressaltam a importância, no trabalho de preparação das famílias adotivas, de incluir discussões sobre temáticas como motivação, idealização e revelação. A reflexão sobre esses aspectos permite explicitar crenças, valores, fantasias, medos, frustrações e projeções diversas, que podem atrapalhar a construção dos vínculos entre pais e filhos na adoção.

É importante trabalhar com as famílias a perspectiva de que a adoção não será um meio de superar frustrações ou de suprir faltas, nem dos adultos e nem das crianças, mas, um processo de construção de vínculos que exigirá muita persistência e resiliência. Nesse sentido, a troca e o compartilhamento de experiências com outras famílias que vivenciam a adoção é parte fundamental do processo.

\begin{abstract}
A preparação em grupos multifamiliares pode gerar oportunidade aos participantes de se conectatem com situações semelhantes, e juntos descobrirem seus medos, angústias, dificuldades, preconceitos e barreiras, assim como desejos e idealizações. Os participantes também descobrirão suas competências e saberes sobre os mecanismos de superação das problemáticas específicas da adoção." (CARDOSO e BAIOCCHI, 2014, p.55)
\end{abstract}

As discussões que ocorrem nesses grupos multifamiliares permitem aos envolvidos ampliarem suas perspectivas sobre o processo da adoção, desconstruindo mitos e preconceitos, refletindo sobre as diversas formas de ser família, acolhendo novas possibilidades, ao rever conceitos e certezas, caminhando em direção à formação da família possível e real. Através dos vínculos formados entre os participantes e do processo de identificações mútuas, vão se configurando novas construções de sentido em relação à 
adoção, o que fortalece os envolvidos e a própria adoção, como forma de ser família.

\section{CONSIDERAÇÕES FINAIS}

A adoção, na atualidade, tem se apresentado como um fenômeno complexo que envolve aspectos psicossociais e jurídicos e articula uma extensa rede que compõem o sistema de garantia de direitos de crianças e adolescentes. A compreensão dessa realidade exige que aqueles que se envolvem com o universo da adoção caminhem, lado a lado, com o entendimento de questões jurídicas e psicossociais que permeiam essa constituição familiar.

Formar uma família pela via da adoção implica em aceitar que esse encontro será intermediado pelo tempo e pelos procedimentos estabelecidos pelo poder judiciário e que as vulnerabilidades, sociais e psíquicas, que afetam crianças, adolescentes e famílias, são aspectos importantes na trajetória desse encontro. Os adultos, que embarcam nessa jornada, devem também refletir sobre suas próprias disponibilidades para o acolhimento e para o estabelecimento desses vínculos familiares.

A escolha pela adoção não implica apenas em um desejo de ter filhos, mas, numa forma específica de tê-los, que traz embutida a necessidade de acolher histórias e vivências anteriores, realizando lutos, também, pela perda dos vínculos biológicos que nesta constituição familiar não serão a sua base. As crianças e adolescentes terão que elaborar o luto pela perda do vínculo com a família biológica e os pais adotivos terão que elaborar o luto pelo fato do seu vínculo com o filho não ser biológico, mas sim socioafetivo. Pais e filhos terão que ressignificar o valor atribuído aos vínculos sanguíneos, construindo seus laços familiares fortalecendo os afetos, desconstruindo mitos e expectativas que não se adequam a realidade vivenciada, abandonando idealizações, superando frustrações, para, enfim, caminharem juntos rumo a uma nova história.

Esse é um processo que precisa de preparação, para que os envolvidos possam refletir sobre as especificidades desse percurso e da família que estão constituindo, fortalecendo-se para os percalços dessa jornada. Nesse sentido, a preparação para a adoção desafia os envolvidos, sobretudo os adultos, a uma revisão de suas crenças, valores e preconceitos, redimensionando seus afetos e reestruturando seus vínculos para estabelecerem-se como família. A adoção deve, então, constituir-se como uma escolha consciente e amadurecida, onde os envolvidos se deparam com suas possibilida- 
des e limites, mas, trabalham para a superação de suas dificuldades e para o aumento de sua capacidade de acolhimento e convivência. Esse não é um processo simples, pois, novas referências deverão ser construídas, até que pais e filhos possam sentir-se confortáveis e plenamente integrados nessa relação. Todos deverão sair de uma "zona de conforto" para abraçar um universo novo e, na maioria das vezes, bem diferente do idealizado anteriormente.

Ao longo desse percurso, ser apoiado por outros, que trilharam o mesmo caminho, e por profissionais que orientam em relação aos aspectos psicossociais e jurídicos dessa trajetória, pode fazer toda a diferença para a superação das dificuldades que surgem ao longo da construção desses vínculos, auxiliando no fortalecimento das relações na família formada. Nesse sentido, a participação nas reuniões promovidas pelos grupos de apoio à adoção tem se mostrado uma estratégia importante para a estruturação desses espaços de apoio, constituindo redes de suportes múltiplos, que atuam em momentos decisivos.

Desta forma, a preparação para a adoção inicia-se como um processo que se insere na habilitação, como etapa obrigatória, mas não se encerra neste momento pontual. De fato, a preparação deve ser continua, uma vez que se constitui como um processo de compreensão das peculiaridades da adoção, de fortalecimento dessa escolha como forma de constituição de laços familiares e de amadurecimento dos envolvidos para os desafios a serem enfrentados nesse percurso. Desafios esses que se iniciam com a escolha do perfil e com as reflexões sobre as motivações para a adoção, mas, continuam após a habilitação, com as angústias do tempo de espera até os encontros iniciais com o filho, sucedem-se para as adaptações que constituem a formação dos primeiros vínculos familiares. Todas essas fases demandam cuidados e devem ser igualmente apoiadas. Assim, o suporte às famílias adotivas não deve ser oferecido apenas no período da habilitação, mas, deve acompanhá-las ao longo de outras etapas importantes de sua constituição, como o período da espera e o do pós-adoção. Esse apoio contínuo pode favorecer o fortalecimento dos vínculos e respeitar as peculiaridades dessa forma de ser família, contribuindo para a garantia do pleno direito à convivência familiar de crianças e adolescentes.

\section{REFERÊNCIAS}

BARTOLATTO, M. O.; LOOS, V. N.; DELVAN, J. S. Grupos de estudo e apoio à adoção e o 
sucesso das adoções. Revista Barbarói, Santa Cruz do Sul, n. 48, Jul/Dez, 2016.

BOHM, C. H.; CAMPOS, N.M.V.; SANTOUCY, L. B.; PEIXOTO, A.P.P.F.; LIMA, M.C.C.; ROCHA, P. F. C.; GURGEL, K. M. R. A preparação psicossocial e jurídica para a adoção no Distrito Federal. Revista Singular: sociais e humanidades, n. 1, Abr. 2019.

BRASIL. Lei n. 8.069 de 13 de Julho de 1990. Dispõe sobre o Estatuto da Criança e do Adolescente e dá outras providências. Brasília. Disponível em: http://www.planalto.gov. br/ccivil_03/leis/l8069compilado.htm

BRASIL. Lei n. 12.010 de 3 de Agosto de 2009. Dispõe sobre a adoção e dá outras providências. Brasília. Disponível em: http://www.planalto.gov.br/ccivil_03/_ato2007-2010/2009/ lei/l12010.htm

CAMPOS, N. M. V. A família nos estudos psicossociais de adoção: uma experiência na Vara da Infância e Juventude do Distrito Federal. Dissertação de Mestrado, Departamento de Psicologia Clinica, Instituto de Psicologia, Universidade de Brasília, Brasília, 2001.

CAMPOS, N. M. V. e COSTA, L. F. A subjetividade presente no estudo psicossocial da adoção. Psicologia: Reflexão e Crítica, 2004, 17(1).

CARDOSO, V. L. e BAIOCCHI, A. Preparação para a adoção: o começo de uma família. Em: LAVOCAT, C. e DIUANA, S. (Orgs.) Guia da Adoção: no jurídico, no social, no psicológico e na família. São Paulo: Roca, 2014.

FONSECA, C. Caminhos da adoção. São Paulo: Cortez, 2006.

MORANI, S. Grupos de apoio à adoção: solo fértil de afeto que semeia e faz brotar o direito de cada criança viver, crescer e pertencer a uma família. Em: BITTENCOURT, S. e TOLEDO, B. (Orgs). Adoção e o direito de viver em família: famílias em concreto e os grupos de apoio à adoção. Curitiba: Juruá, 2017.

SIQUEIRA, V. C. e STELLA, C. Preparação para a adoção: grupo de apoio para candidatos. Revista Psicologia: Teoria e Prática, 16(1), São Paulo, Jan-Abr, 2014.

SOUSA, W.G. A inquestionável eficácia do curso de preparação para a adoção no DF. Disponível em: https://www.tjdft.jus.br/informacoes/infancia-e-juventude/publicacoes-textos-e-artigos/textos-e-artigos/a-inquestionavel-eficacia-do-curso-de-preparacao-para-adocao-no-df Acesso em 13/01/2020

SOUZA, H. P. e CASANOVA, R. P. S. Adoção e a preparação dos pretendentes: roteiro para o trabalho nos grupos preparatórios. Curitiba: Juruá, 2014.

WEBER, L. N. D. Aspectos psicológicos da adoção. Curitiba: Juruá, 2009. 


\section{Monica de Vasconcellos Dias}

Doutora em Psicologia Clínica pela PUC-Rio; Professora do Curso de Graduação em Psicologia da Universidade Veiga de Almeida; Especialista em Psicologia Jurídica pela UCAM; Psicoterapeuta com formação em Família e Casal; uma das coordenadoras do Grupo de Apoio Catedral da Adoção, Rio de Janeiro.

E-mail: monivas.diaso@gmail.com 